\title{
Regional differences in reasons for consultation and general practitioners' spectrum of services in Northern Germany - Results of a cross-sectional observational study
}

\section{Ingmar Schäfer}

University Medical Center Hamburg-Eppendorf, Department of General Practice/Primary Care

Heike Hansen ( $\nabla$ h.hansen@uke.de)

Department of General Practice/Primary Care https://orcid.org/0000-0003-4901-3091

\section{Thomas Ruppel}

The University of Melbourne Department of General Practice

\section{Dagmar Lühmann}

Universitatsklinikum Hamburg-Eppendorf

\section{Hans-Otto Wagner}

University Medical Center Hamburg-Eppendorf, Department of General Practice/Primary Care

\section{Agata Kazek}

University Medical Center Hamburg-Eppendorf, Department of General Practice/Primary Care

\section{Martin Scherer}

University Medical Center Hamburg-Eppendorf, Department of General Practice/Primary Care

\section{Research article}

Keywords: General practice, Reasons for consultation, General practitioners' spectrum of services, Regional comparison, Urban-rural differences

Posted Date: November 11th, 2019

DOI: https://doi.org/10.21203/rs.2.16496/v2

License: @ (i) This work is licensed under a Creative Commons Attribution 4.0 International License. Read Full License 


\section{Abstract}

Background Among other factors, the patients' consultation reasons and GPs' spectrum of services determine the process and outcome of the medical treatment. So far, however, there has been little information on differences in reasons for consultation and GPs' services between urban and rural areas. Our study's goal was thus to investigate these factors in relation to the regional location of GPs' practices.

Methods We conducted a cross-sectional observational study based on standardised GP interviews in a quota sampling design. All counties and independent cities within a radius of $120 \mathrm{~km}$ around Hamburg were divided into three regional categories (urban area, environs, rural area) and stratified proportionally to the population size. Differences in the number of reasons for consultation and services were analysed by multivariate linear regressions in mixed models adjusted for random effects on the levels of the German federal states and administrative districts. Differences in individual consultation reasons and services were identified by logistic regression via stepwise forward and backward selection.

Results Primary care practices in 34 of the 37 selected administrative districts (91.9\%) were represented in the dataset. In total, 211 GPs were personally interviewed. On average, GPs saw 344 patients per month with a slightly higher number of patients in rural areas. They reported $59.1 \pm 15.4$ different reasons for consultation and $30.3+3.9$ different services. There was no statistically significant regional variation in the number of different consultation reasons, but there was a broader service spectrum by rural GPs ( $B=-1.42 ; 95 \%$ confidence interval $-2.75 /-0.08 ; p=0.038)$ which was statistically explained by a higher level of medical training. Additionally, there were differences in the frequency of individual consultation reasons and services between rural and urban areas.

Conclusion GPs in rural areas performed more frequently services usually provided by medical specialists in urban areas. This might be caused by a low availability of specialists in rural areas. The association between medical training and service spectrum might imply that GPs compensate the specific needs of their patients by completing advanced medical training before or after setting up a medical practice.

Trial registration The study was registered in ClinicalTrials.gov (NCT02558322).

\section{Background}

In well-developed health care systems, there is rational health care planning based on available data. However, not all relevant data are normally used for this process. In Germany, for example, the regional associations of statutory health insurance physicians and the regional federations of the statutory health insurances are obliged to perform mutual needs-related planning of the number of accredited physicians within the statutory health insurance system. In order to prevent an over- and undersupply of physicians, ratios of the number of physicians in different specialties and the population size in specific planning areas are defined. These ratios can be adapted to special features of the region or the regional infrastructure, especially if other planning areas contribute to health care in the respective area. Other criteria for deviating from these ratios are regional data on morbidity, sociodemographic parameters or socioeconomic status of the population [1].

On the one hand, according to these criteria, there are substantial regional disparities. For example, diabetes and obesity are more prevalent in rural areas [2] while depressive disorders play a slightly larger role in core cities [3]. Age groups differ largely between East and West Germany as well as between urban and rural areas [4]. Additionally, from a socioeconomic perspective, there are inconsistent regional differences between urban and rural areas. For example, while highly qualified jobs are concentrated in the centres of urban areas [5], there is also simultaneously a significantly higher spending capacity adjusted income poverty in urban areas [6]. 
On the other hand, not all factors relevant for the utilisation of health care are covered by these criteria. For example, barriers and enablers for access to health care differ between the regions. The preliminary qualitative study of the analysis presented here reported that GPs and patients in rural areas frequently discussed long distances to the doctor's office, long waiting times and the GPs' large workload. In contrast, high patient fluctuation and fierce competition among GPs were frequent topics of discussions in urban areas [7].

There were also regional differences in patient behaviour and GPs' understanding and perception of their role. Patients in rural areas seemed to consult their GP relatively late in urgent consultation matters, while a certain fraction of the patients in cities already consulted their GP for banalities [7]. Furthermore, GPs in rural areas were more likely to identify themselves as family doctors and persons of trust for their patients while their role as medical service provider and referrer to specialists was more emphasised in urban areas [8].

These aspects are very likely linked to regional variations of patients' reasons for consultation and GPs' spectrum of services, which also determine process and outcome of the medical treatment. A study by Steinhäuser et al. showed clear differences between rural and urban GPs regarding 25 of the 42 most frequently carried out procedures (such as "ambulatory blood pressure monitoring" or "adolescent examinations") [9]. So far, however, there has been relatively little information on the difference in reasons for consultation and services between urban and rural areas. Thus, the goal of the study presented here was to investigate reasons for consultation and services of GPs in relation to the regional location of their practices in Northern Germany.

\section{Methods}

The project "Outpatient Healthcare Research North (Ambulante Versorgungsforschung Nord - AVFN)" was designed as a cross-sectional observational study. Methods, research hypotheses and statistical models had been described in the study register ClinicalTrials.gov (NCT02558322) before starting the survey and in the published study protocol [10]. Although our study has been based on GP and patient interviews, the analysis presented here includes GP data only.

Three categories had been defined for the regional comparison according to the so-called "structural settlement of district types" of the German Federal Institute for Research on Building, Urban Affairs and Spatial Development [11]. The category "urban areas" included urban municipalities, the category "environs" urbanised districts and rural districts with signs of agglomeration, and the category "rural areas" sparsely populated rural districts.

A quota sampling design was chosen to represent as many regionally different healthcare situations in the study area as possible. The purpose of this design was to raise the probability of also including underserved regions into the study where usually many GPs were unwilling to participate in a study due to their heavy workload. The goal was to recruit at least 80 GPs per regional category for the project-categorised by individual administrative districts (counties and independent cities) and proportionally to the respective population size in the districts [10].

At first and for determining the survey area, all administrative districts were included in the study where at least $20 \%$ of the land area was located within a radius of $100 \mathrm{~km}$ (ca. 62 miles) linear distance around the study centre (University Medical Centre Hamburg-Eppendorf). As initially, despite regular follow-up actions, the desired sample size of $240 \mathrm{GPs}$ could not be achieved, the radius around the study centre was expanded to $120 \mathrm{~km}$ (ca. $75 \mathrm{miles}$ ) according to the approach described in the study protocol [10]. The thus chosen administration districts for the study were derived from the German Federal States of Bremen, Hamburg, Mecklenburg-Western Pomerania, Lower Saxony, Saxony-Anhalt and Schleswig-Holstein.

GPs' recruitment was based on a database of the Department of General Practice at the University Medical Centre Hamburg-Eppendorf as well as on the databases of the respective regional associations of statutory health insurance 
physicians in the selected areas. GPs were eligible for the study if they had an accreditation as statutory health insurance physician in the respective administrative district and used an EDP system facilitating to draw up a list of all patients treated over the preceding quarter (3-month accounting period).

Eligible GPs were contacted in writing by mail and asked to participate in the study. Participating GPs were visited by a staff member of the project and personally interviewed. In rare cases, it had been impossible to completely finish the GP's interview during the office visit for lack of time. Regarding these cases, the interview was later completed by telephone. Data were supplied by memory recall. However, GPs were allowed to check their files if they considered it necessary.

The interviews were based on standardised questionnaires and contained information regarding the GPs' age ( 1 item), gender (1 item), workload (3 items), and postgraduate and advanced medical training (2 items) as well as data on the practice (4 items). Additionally, 99 different reasons for consultation from 17 areas / organ systems and healthcare services involving 38 different procedures were documented by means of a standardised instrument developed on the basis of the International Classification of Primary Care (ICPC-2) [10;12-13]. These data were described as the proportion of the respective consultation reasons or the respective services of all consultation reasons or services documented at the respective practice. The GP questionnaire also contained some items not reported here, ie, the GPs' place of residence ( 1 item) and professional experience (4 items) as well as the number of weekly contacts with 27 patient types. The GPs' survey was conducted from 12 June 2015 to 27 April 2017.

Regional differences were initially described using the chi-square test and t-test. The number of different consultation reasons and the GPs' service spectrum were subsequently analysed by means of multivariate linear regressions in mixed models adjusted for random effects on the levels of the German federal states and administrative districts within the federal states. In these analyses, the control variables were stepwise included in three statistical models. A potential improvement of the model fit was determined by the likelihood ratio test.

To be able to interpret these results better, significant differences in reasons for consultation and services between urban areas, environs, and rural areas were identified by logistic regression analyses via stepwise forward and backward selection with $p \leq 0.05$ as inclusion and $p \leq 0.10$ as exclusion criterion. Variables showing characteristic values of a lower frequency than 1\% had been excluded in advance. Thus, 14 ICPC 2 areas / organ systems, 29 different reasons for consultation and 22 different services remained in the statistical models for selecting variables.

An alpha level of $5 \%(p \leq 0.05)$ was defined as statistically significant for all analyses of the inferential statistics. Stata 15.1 was used for data preparation and data analysis.

\section{Results}

In our quota sampling design, we were able to adhere to the stratification rules defined in the study protocol. Figure 1 shows a map of the respective regions. Primary care practices in 34 of the 37 selected administrative districts (91.9\%) were represented in the dataset. No study participants could be recruited from three districts of the environs, ie, Delmenhorst, Diepholz and Osterholz. Initially, we recruited $280 \mathrm{GPs}$ from the selected regions. However, interviews could not be carried out with 69 study participants due to time-related or organisational reasons (eg, sick primary care partners, problems with the patient management software). In the end, we were able to personally interview $211 \mathrm{GPs}$. Tables A1 to A3 of the additional files describe the recruitment process of the stratification groups. In total, $12 \%$ of GPs in urban areas, $13 \%$ of GPs in the environs, and $25 \%$ of GPs in rural areas had to be recruited from other stratification groups of the respective regional category than originally planned. 
The sociodemographic data, the number of treated patients, and the professional qualification of the interviewed GPs are shown in Table 1. The GPs' average age was 54.5 years and $65.4 \%$ of GPs were male. On average, GPs saw 344 patients per month with a slightly higher number of patients in rural than in urban areas. In Germany, GPs can work individually in private practices (individual practice) or together with other physicians-either in private practices where each physician submits his own claims (group practice) or in private practices where the claims of all physicians are combined and submitted as one bill (joint practice). In our study, GPs mostly worked in individual or joint practices and less frequently in group practices or medical care centres ("Medizinische Versorgungszentren”, MVZ). Individual practices were noticeable more frequently found in rural than in urban areas and in our sample, group practices including MVZ had been solely located in urban areas and the environs.

77.3\% of GPs had completed general medicine postgraduate specialist training and $23.2 \%$ had completed internal medicine postgraduate specialist training. The postgraduate training "general medicine specialist" was reported more often in rural areas than in the environs and the postgraduate training "internal medicine specialist " was reported less often in rural areas than in the environs. $6.6 \%$ of GPs reported that they had not completed a postgraduate specialist training. On average, GPs additionally reported advanced medical training in 1.5 areas. The most frequent advanced medical training was in emergency care and palliative medicine. $31.8 \%$ of GPs had not completed an advanced medical training.

Table 2 shows the average relative rate of individual consultation reasons of all reported reasons for consultation. Most frequently, GPs described reasons for consultation from the ICPC 2 areas / organ systems "cardiovascular system", "musculoskeletal system" and "endocrine/metabolic and nutritional". In total and on average, GPs reported $59.1 \pm 15.4$ different reasons for consultation that had been addressed by their patients during consultation at least once per month.

A multivariate analysis adjusted for age and gender showed no statistically significant regional variation in the number of different consultation reasons (see Table A4 of the additional files). However, the stepwise variable selection showed that reasons for consultation from the areas "ear" (odds ratio (OR) 1.42; $p=0.046$ ), "skin" (OR 1.38; $p=0.013$ ) and "musculoskeletal system" (OR 1.13; $p=0.003$ ) as well as the consultation reason "lymph/lymphoedema in the leg, chronic wounds" (OR 1.78; $p=0.006$ ) were more often reported in rural than in urban areas. On the other hand, consultation reasons from the area "social problems" (1/OR 1.19; $p=0.006)$ were less frequently reported in rural than in urban areas. Additionally, "shoulder problems" (OR 1.50; $p=0.005)$ were reported more often in rural areas than in the environs and "acute infections of the respiratory tract" (1/OR 1.10; $p=0.024)$ were less frequently reported in rural areas than in the environs.

Table 3 shows the average relative rate of the individual services of all reported services. The most frequently reported services were "blood test", "referral to a specialist" and "continuous care for the chronically ill". The average number of different services provided was $30.3+3.9$. Compared to urban areas, a somewhat broader spectrum of services was reported in rural areas (31.1 \pm 3.7 vs. $29.4 \pm 3.9 ; p=0.010)$.

This difference was, at first, confirmed by the multivariate multilevel analysis controlled for age and gender (see Table 4). However, after including postgraduate and advanced medical training, the regional difference disappeared and the model fit improved significantly $(p=0.021)$, ie, the second statistical model fit our data better than the first model. In contrast, the additional inclusion of practice type and number of patients treated per month produced neither significant changes in the estimates of the other independent variables nor a further improvement of the model fit $(p=0.502)$. The stepwise selection of variables showed that the service "local injection / infiltration" (OR 1.26; $p=0.046$ ) was more frequently reported in rural than in urban areas and the services "check-up 35" (1/OR 1.47; $p=0.013)$, "psychosomatic primary care" (1/OR 1.20; $p=0.003)$ as well as "lifestyle counselling, social counselling" $(1 /$ OR $1.11 ; p=0.003)$ were 
less frequently reported in rural than in urban areas. Additionally, "urine analysis" $(O R=1.12 ; p=0.028)$ was more frequently reported in rural areas than in the environs.

\section{Discussion}

Main findings

In our study, GPs from regions of different degrees of urbanisation reported how often their patients had presented specific reasons for consultation and how often GPs had responded with providing different services. In total, the number of different reasons for consulting GPs was similar in urban and rural areas however, the frequency of individual reasons for consultation had been different. In contrast, GPs from rural areas performed a larger number of different services than GPs from urban areas. Comparable to the analysis of consultation reasons, the frequency of the individual services also differed between the regional categories.

On the one hand, our study suggests that GPs in rural areas spent less time on communicative, preventive, and consultative medicine than GPs in urban areas. On the other hand, GPs in rural areas more often reported performing services that are usually provided by specialists in urban areas. GPs' postgraduate and advanced medical training seemed to play an important role for the service spectrum offered by GPs. The multivariate models showed that the broader spectrum of services reported by rural GPs was statistically explained by a higher level of medical training.

Strengths and limitations of the survey

GPs' recruitment was not carried out by random selection but by quota sampling. By adhering to the $25 \%$ maximum deviation from the recruitment plan defined in the study protocol [10]-we were able to include $91.9 \%$ of the selected administrative districts into our study as well as GPs from less-favoured areas difficult to reach by means of transport, such as Kalbe (Milde) or Helgoland. Disadvantages of quota sampling were that, in some districts, many GPs had to be contacted to adhere to the stratification plan while in other districts the recruitment process had to end early without follow-up and not all GPs willing to participate could be included in the study. Thus, the high number of 4,956 contacted GPs and the comparatively low participation rate of $4.3 \%$ interviewed GPs. Despite the fact that-by definition-the participation rate is not important in quota sampling, it may still affect the representativeness of the GP population. However, it should be noted that the response rate is not the only indicator for a selection bias. Regarding our study, we deem quota sampling the preferable method over random sampling to represent the regionally different healthcare situations because we believe the variation between medically underserved and oversupplied districts to be greater than the variation between GPs within the districts.

Additionally, although random selection is a better known and clearly more frequently used method, studies have shown quota sampling not necessarily to be linked to a larger selection bias than random sampling [14]. To gather some information on a possible selection bias, we performed a comparison of the data of study participants in the included regions with the statistics of the German national association of statutory health insurance physicians. This analysis showed, with one exception, only relatively minor deviations. Thus, GPs participating in our study had only been slightly older (urban areas: +0.9 years; environs: +0.4 years; rural areas: +0.6 years) and slightly more often males than the basic study population of the selected districts (urban areas: $+3.6 \%$; rural areas: $+3.6 \%$ ). A more distinct selection bias was found regarding the GPs' gender in the environs where the proportion of men compared to the basic study population had increased by 15.6 percentage points [15].

Besides the uneven gender distribution, there is one more aspect of the regional category "environs" that needs to be discussed. "Environs", by definition, include urbanized districts and rural districts with signs of agglomeration. However, our data suggest that, depending on the analysed item, features of primary care in the environs are either similar to 
"urban areas" or similar to "rural areas" (eg, the rate of the consultation reason "social problems" is similar to rural areas while the rate of the service "lifestyle counselling, social counselling" is comparable to urban areas). Therefore, "environs" should be considered a mixed category and findings regarding this regional category need to be interpreted with care.

The statistical methods provided additional strength by considering potential confounders and the cluster structure of the dataset. Aside from the two multivariate analyses on the range of reasons for consultation and services used for analysing the main question of this study, the stepwise variable selection also identified regional differences in the individual reasons for consultation and services. It should be noted that this approach reacts sensitively to differences in the distribution of the variables. The identified model thus might not necessarily be the best set of variables to describe the regional differences in individual services and consultation reasons. As the explained variance had been relatively low (the pseudo- $\mathrm{R}^{2}$ averaged 0.091 ), there might also be other important differences between the regions as shown in the identified predictors.

As in all studies based on interviews, the physicians' answers might also have been influenced by memory gaps, errors or social desirability. This relates, in particular, to the assessment of the consultation reasons and the service spectrum which were mainly retrieved from memory. It should also be noted that 12 of the $211 \mathrm{GP}$ interviews (5.7\%) were completed by telephone which might have impaired detail of the GPs' answers. However, using interview data facilitated a series of analyses that would not have been possible on the basis of routine data. For example, services paid by flat rate could be depicted individually in our study and reasons for consultation, such as "social problems" which are difficult to code in ICD-10, could be recorded. Another limitation is the fact that the recruitment area has been restricted to northern Germany and the results therefore do not necessarily represent the remainder of Germany. As this was an observational study with multiple outcomes, we were unable to carry out a sample size calculation and therefore might have missed some differences between the regions due to limited statistical power.

Comparison with literature and discussion of results

Our study suggests that the frequency of the individual reasons for consultation differ between urban and rural areas. Compared to urban areas, fewer consultations for "social problems" were reported in rural areas indicating that GPs in urban areas probably had to provide more psychosocial support for their patients than GPs in rural areas. This could be the result of regionally different housing situations. One of the results of the EU contribution to the World Mental Health Surveys Initiative was that life in urban areas seemed to increase the risk of affective disorders [16]. An analysis of statutory health insurance physicians' billing data also reported on the increased prevalence of depressive disorders in German core cities [3].

"Acute infections of the respiratory tract" had also been reported less frequently in rural areas than in environs. This may be an indication that social medical tasks, such as issuing a statement of illness, are given higher priority in districts with a higher degree of urbanisation than rural areas. This point had already been stated by some participants of our preliminary qualitative study by saying that GPs in urban areas were often only perceived as medical service providers or referrers to other specialists [8].

In Germany, patients are permitted to consult specialists without the referral from a GP. In our study, GPs in rural areas more often reported reasons for consultation for which urban patients probably would have directly used the services of a specialist, primarily concerning orthopaedics, dermatology and otorhinolaryngology. This finding might be explained by the different regional availability of physicians in outpatient care. On average, rural areas included in this study only showed a lower density of ca. $10 \%$ of physicians in primary care but a $40 \%$ to $50 \%$ lower density of ophthalmologists, ENT specialists and orthopaedists in comparison to urban areas or environs [15]. 
GPs in rural areas reported to treat a larger number of patients and to offer a broader spectrum of services than GPs in urban areas. Other studies showed the same results. Steinhäuser et al., for example, reported that GPs in rural areas carried out a broader range of procedures, particularly those usually playing a role in specialist care [9]. As early as 1998, Boerma et al. investigated regional differences in the spectrum of services provided by GPs from 30 European countries and described a more comprehensive range of services by primary care practices in rural areas and indicated a smaller role as gatekeeper of the inner city primary care practices [17]. Mehring et al. also described a higher ratio of coordinated care by GPs of patients from rural areas [18]. Additionally, a study on the treatment of bowel cancer highlighted a greater involvement of GPs from rural areas in coordinating care as well as clinical and psychosocial support for patients in rural areas [19].

Our study also showed differences in the type of individual services. The more frequent mentioning of "local injection / infiltration" or "urine analysis" in rural than in urban areas or environs might be interpreted as an indication that classic somatic primary care services had been carried out more frequently in rural than in urban areas or environs. House calls had also been reported more frequently in rural than in urban areas. Pochert et al. also described this regional difference in their study on the house call workload of GPs in Germany. Their study showed an average number of 16.5 house calls per week in rural areas whereas only 12.5 house calls per week were carried out in urban areas [20].

Regarding the level of services, GPs in urban areas placed greater emphasis on psychosocial support. A study by Görig et al. showed that GPs in rural areas offered fewer lifestyle consultations for preventing cardiovascular disorders than GPs in cities [21]. As already mentioned, there is a higher prevalence of psychological disorders, such as depression or anxiety disorders in urban than in rural areas [22-23]. This may lead to the conclusion that GPs from urban regions have to provide psychosocial services for the care of these patients more frequently.

\section{Conclusion}

Our study pointed out a number of regional differences that might be relevant for health care planning, particularly regarding the services provided in rural and urban areas. GPs in rural areas, for example, spent less time on preventive medicine than GPs in urban areas. This might indicate a shortage of preventive services in rural areas. Likewise, access to psychotherapy and psychosocial support in urban areas is also generally better than in rural areas. Just under $25 \%$ of the German population lives in cities compared to almost $50 \%$ of Germany's psychotherapists who practise in cities [26]. However, GPs from urban areas still spent more time on psychosocial support than GPs from rural areas. This might indicate a underassessment of psychosocial problems in rural areas.

Our study suggests that GPs in rural areas more frequently provide services that are usually part of specialist care. This may be the result of a low availability of specialists in rural areas, which has been widely discussed in literature $[27,15]$. There are many approaches that may help motivating young physicians to work in rural areas, such as improving rural infrastructure. But as there are generally too few young physicians, other strategies should also be taken into consideration, eg, telemedicine, mobile practices or delegation of medical services. In our study, GPs in rural areas mostly worked in individual practices while GPs in regions with a higher degree of urbanisation more often worked in group and joint practices or medical care centres. This might be the result of the lower mean age of GPs working in urban areas as practices with a larger staff of physicians usually provide better and more family-friendly working conditions, which might be more appealing to young physicians.

Another finding that might be relevant in this context was the fact that rural GPs' broader service spectrum was statistically explained by a higher level of medical training. On the one hand, this result might imply that GPs from rural areas compensated for specific needs of the regional patient population by completing relevant advanced medical training. On the other hand, this might also imply that predominately GPs with advanced medical training were drawn to 
rural areas, eg, because they felt better prepared for the local conditions. Further research is needed to clarify the role of medical training for interventions addressing the shortage of rural GPs.

\section{List Of Abbreviations}

EDP: electronic data processing; ENT: ear, nose, and throat; GP: General practitioner; ICPC-2: International Classification of Primary Care

\section{Declarations}

Ethics approval and consent to participate

The study was approved by the Ethics Commission of the Hamburg Medical Association on 12 August 2013 (file number PV 4535). All study participants gave their written informed consent prior to their participation in the study.

Consent for publication

All participants gave their written consent to publish their names in the 'Acknowledgements' section.

Availability of data and material

The datasets analysed during the current study are not publicly available as data sharing with other researchers was not part of patients' informed consent.

Competing interests

The authors declare that they have no competing interests.

Funding

The study was supported by the Hamburg and Schleswig-Holstein Association of Statutory Health Insurance Physicians. The funding body had no role in the design of the study and collection, analysis, and interpretation of data and in writing the manuscript.

Authors' contributions

MS, IS and HH conceived and designed the study. DL, HOW, TR and AK significantly contributed to the study design and/or discussion of the study results. IS analysed the data. IS and HH drafted the manuscript. All the authors commented on the draft and read and approved the final version of the manuscript.

Acknowledgements

We would like to express our appreciation to the numerous GPs who facilitated this study with their participation, namely: Karl-Heinz Aeffner, Volker Ahrens, Susanne Assmus, Ayhan Ayikli, Aina Barbakow, Hellmut Baur, Nina Becker, Gunter Behrend, Sven Behrens, Daisy Benson, Ulrich Berghof, Friederike Besch, Jürgen Biesewig-Siebenmorgen, Claudia Bleil, Karen Blumenbach, Eckart Boehnke, Ulrike Börgerding, Hans Böttcher, Marcus Brand, Jens Bräuer, Nicolay Breyer, Broder Brodersen, Peter Brümmer, Paola Brusa Düwel, Christian Butt, Kerstin Dann, Natascha Dannheisser, Susanne Dennig, Christian Dettmann, Björn-Ole Dieckvoß, Frank Döhling, Markus Dohrmann, Gero Domzig, Sabine Drengenberg, Thomas Drescher, Norbert Eckhardt, Henning Eggers, Jürgen Elis, Heike Elsen, Michael Emken, Susanne Faas-Ramm, Heino Feldbrügge, Matthias Fischer, Thomas Flasinski, Christiane Fock, Kurt Forstreuter, Dorothea Frederking, Dierk 
Freundl, Clemens Frey, Frank Fueting, Inka Führer, Michael Funke, Ralf Gade, Jan Geldmacher, Birgit Gier-Moser, Dagmar Gottkehaskamp, Daniel Graf, Inga Grimm, Carmen Cecilia Groninga, Peter Gründahl, Christine Gschwend, Nils Hansen, Henning Harder, Regina Hartwig-Haars, Ruth Hauck, Rudolf Hauschildt, Jürgen Hausmann, Henrik Heinrichs, Beate Heitmann, Rainer Hennecke, Franz Herrschel, Wolfgang Herzog, Corinna Hess, Ulrike Heye, Pamela Hilgenberg, Bernd Hinz, Andreas Hofinga, Herbert Hofstetter, Karl Heinz Houcken, Charlotte Hübner-Urch, Peter Humbert, JanaHusemann, Claus Jaeckel, Markus Jäger-Rosiny, Heinz Jarmatz, Claudia Kahle, Lars Kämpfer, Stefan Kasischke, Dieter Kayser, Carlos Keller, Christiane Kindler-Behrens, Bernd Klemeyer, Michael Klemperer, Hans-Peter Knapp, Martina Koch, Dorothea Koersten, Stefan Köhn, Martin Kohne, Daniel Körbacher, Thomas Kötter, Toni Koudmani, Stefan Kreszis, Ute Lang, Raimund Leineweber, Nicole Lenzi-Sommer, Andreas Lindrum, Andrea Linsel, Thomas Loeseken, Daniel Lohmann, Margret Lorenzen, Berit Löwnau, Elisabeth Lübbers-Klare, Mirko Magens, Claudia Malchartzeck, Helmut Marczinkowski, Frank Meisel, Anne Meister, Albrecht Meister, Dagmar Menche, Wolf-Dieter Mengert, Hans-Georg Merkel, Ingo Migule, Andreas Mittelstädt, Eckart Möbius, Frank Möller, Rio Morawe, Mike Müller- Glamann, Karl-Christian Münter, Anila Nasery, Klaus-Peter Neizel-Tönnies, Marcus Netzel, Jonas Niemann, Birgit Obermeier, Michael Odinius, Swantje Ohlen, Ilse Ordemann, Irina Osinski, Christiane Otto, August Palatsik, Werner Petersen, Jürgen Pohl, Claudia Polay-Hehn, Uwe Pönnighaus, Dirk Rappenberg, Dirk Reese, Karin Rehder, Rainer Reiß, Friedel Rennekamp, Marlies Richter-Boehnke, Thomas Rohlfing, Ulrich Rose, Detlef Roshop, Anja Roß, Beatrice Roßbach, Janet Rossmann, Wolfgang Rumpf, Jörg Runge, Gerd Ruß, Detlef Schäfer, Peter-Andreas Schaper, Hans-Georg Schoermer, Manfred Schopf, Uta Schramm, Udo Schröder, Simon-Vitus Schuknecht, Walter Schulz, Susann Schütt, Jörg Schwarzkopf, Louis Sellier, Olaf Settgast, Helena Simov, Carsten Sommerfeld, Bettina Sponheim-Rambow, Maren Stadtlander-Rahm, Manfred Steinkohl, Andrea Stendel, Elke Sterling, Hans-Heiner Stöver, Ulrike Streit, Stefan Strzelec, Thomas Szlagowski, Georg Tacke, Gerrit Tarrach, Arjen Teetzmann, Silke Theisen, Jens Thomä, Bernd Thormählen, Sevine Tokdemir, Michael Topp, Matthias Trenkler, Thomas Tschirner, Christian Vahle, Martin Richard Vietor, Martina Vogler, Volker Voß, Meike Wagner, Jens Wagner, Doris Waller, Thomas Wasielewski, Jan Philip Wegner, Katrin Welke, Matthias Will, Sven-Ullrich Winter, Henning Winter, Delia Wirth, Lutz Witte, Anja Wittke, Thomas Wittke, Klaus Wogawa, Siegmar Zedler, Alexandra Zeidler, Eckhard Zeigert, Martin Zingel, Matthias Zink, Constantin Zoras and Nicole Zühlke.

\section{References}

1.Kassenärztliche Bundesvereinigung. Die Bedarfsplanung als Instrument zur Sicherstellung der ambulanten Versorgung. https://www.kbv.de/html/bedarfsplanung.php. Accessed 24.9.2019.

2.Kroll LE, Lampert T. Regionale Unterschiede in der Gesundheit am Beispiel von Adipositas und Diabetes mellitus. In: Robert Koch-Institut (Hrsg.) Daten und Fakten: Ergebnisse der Studie» Gesundheit in Deutschland. Berlin, 2010: 51-59. http://www.gbe-bund.de/pdf/GEDA_2010_5_Adipositas_Diabetes_mellitus.pdf. Accessed 17 Jan 2019.

3.Erhart M, von Stillfried D. Analyse regionaler Unterschiede in der Prävalenz und Versorgung depressiver Störungen auf Basis vertragsärztlicher Abrechnungsdaten-Teil 1 Prävalenz. Berlin: Zentralinstitut für die kassenärztliche Versorgung in Deutschland, 2012.

4.Steffen Maretzke. Regionale Unterschiede in der Altersstruktur. In: Leibniz-Institut für Länderkunde, Kemper FJ, Gans P (Hrsg.). Bundesrepublik Deutschland: Nationalatlas. Band 4. Bevölkerung. Heidelberg: Springer Spektrum, 2012.

5.Weishaupt H. Bildung und Region. In: Rudolf Tippelt Bernhard Schmidt (Hrsg.). Handbuch Bildungsforschung. 3., durchgesehene Auflage. Wiebaden: VS Verlag für Sozialwissenschaften, 2010; 217-232.

6.Institut der Deutschen Wirtschaft. Einkommensarmut in Deutschland aus regionaler Sicht. Pressekonferenz 25. August 2014. https://www.iwkoeln.de/presse/presseveranstaltungen/beitrag/pressekonferenz-einkommensarmut-in- 
deutschland-aus-regionaler-sicht-179584.html. Accessed 24.9.2019.

7.Hansen H, Pohontsch NJ, Bole L, Schäfer I, Scherer M. Regional variations of perceived problems in ambulatory care from the perspective of general practitioners and their patients - an exploratory focus group study in urban and rural regions of northern Germany. BMC Fam Pract. 2017;18:68.

8.Pohontsch NJ, Hansen H, Schäfer I, Scherer M. General practitioners' perception of being a doctor in urban vs. rural regions in Germany - A focus group study. Fam Pract. 2018;35:209-215.

9.Steinhäuser J, Jäkel K, Szecsenyi J, Goetz K, Ledig T, Joos S. Procedures Performed in General Practice - a Crosssectional Study. Gesundheitswesen. 2017;79:1004-1011.

10.Schäfer I, Hansen H, Pohontsch N, Bole L, Wagner HO, Führ M, Lühmann D, Scherer M. Regional variation of patient behaviour and reasons for consultation in the general practice of Northern Germany: protocol for an observational study. BMJ Open. 2016;6:e010738.

11.Bundesinstitut für Bau- Stadt- und Raumforschung. Siedlungsstrukturelle Kreistypen - Laufende Raumbeobachtung Raumabgrenzungen.

http://www.bbsr.bund.de/nn_1067638/BBSR/DE/Raumbeobachtung/Raumabgrenzungen/Kreistypen4/kreistypen.html. Accessed 17 Jan 2019.

12.WONCA International Classification Committee. ICPC-2-R: International Classification of Primary Care. Revised 2nd ed. Oxford: Oxford University Press 2005.

13.Körner T, Saad A, Laux G, Rosemann T, Beyer M, Szecsenyi J. Die Episode als Grundlage der Dokumentation. Eine episodenbezogene Patientenakte mit einer speziell für die Allgemeinmedizin entwickelten Klassifikation verbessert die Datenbasis in der hausärztlichen Versorgung. Dtsch Arztebl. 2005;100:A3168-72.

14.Cumming RG. Is probability sampling always better? A comparison of results from a quota and a probability sample survey. Community Health Stud. 1990;14:132-7.

15. KBV (Kassenärztliche Bundesvereinigung). Gesundheitsdaten: Regionale Verteilung der Ärzte in der vertragsärztlichen Versorgung. http://gesundheitsdaten.kbv.de/cms/html/16402.php. Accessed 15 Jan 2019.

16.Pinto-Meza A, Moneta MV, Alonso J, Angermeyer MC, Bruffaerts R, Caldas de Almeida JM, de Girolamo G, de Graaf R, Florescu S, Kovess Masfety V, O’Neill S, Vassilev S, Haro JM. Social inequalities in mental health: results from the EU contribution to the World Mental Health Surveys Initiative. Soc Psychiatry Psychiatr Epidemiol. 2013;48:173-81.

17.Boerma WG, Groenewegen PP, Van der Zee J. General practice in urban and rural Europe: the range of curative services. Soc Sci Med. 1998;47:445-53.

18.Mehring M, Donnachie E, Schneider A, Tauscher M, Gerlach R, Storr C, Linde K, Mielck A, Maier W. Impact of regional socioeconomic variation on coordination and cost of ambulatory care: investigation of claims data from Bavaria, Germany. BMJ Open. 2017;7:e016218.

19. Hanks H, Veitch PC, Harris MF. A rural/urban comparison of the roles of the general practitioner in colorectal cancer management. Aust J Rural Health. 2008;16:376-82.

20.Pochert M, Voigt K, Bortz M, Sattler A, Schübel J, Bergmann A. The workload for home visits by German family practitioners: an analysis of regional variation in a cross-sectional study. BMC Fam Pract. 2019;20:3.

Page $11 / 17$ 
21.Görig T, Diehl K, Herr RM, Bock C, Mayer M, Schneider S. [Differences in the Provision of Lifestyle Counseling for Cardiovascular Disease Prevention Between Urban and Rural Regions in Germany. Findings from a National Survey of Primary Care Physicians]. Gesundheitswesen. 2016;78:533-8.

22.Wiens K, Williams JV, Lavorato DH, Bulloch AG, Patten SB. The Prevalence of Major Depressive Episodes Is Higher in Urban Regions of Canada. Can J Psychiatry. 2017;62:57-61.

23.Peen J, Schoevers RA, Beekman AT, Dekker J. The current status of urban-rural differences in psychiatric disorders. Acta Psychiatr Scand. 2010;12184-93.

24.Kim C, McEwen LN, Gerzoff RB, Marrero DG, Mangione CM, Selby JV, Herman WH. Is physician gender associated with the quality of diabetes care? Diabetes Care. 2005;28:1594-8.

25.Baumhäkel M, Müller U, Böhm M. Influence of gender of physicians and patients on guideline-recommended treatment of chronic heart failure in a cross-sectional study. Eur J Heart Fail. 2009;11:299-303.

26.Albrecht M, Etgeton S, Ochmann RR. Facktencheck Gesundheit-Regionale Verteilung von Arztsitzen (Ärztedichte)HNO-Ärzte, Nervenärzte, Orthopäden, Psychotherapeuten, Urologen. https://www.bertelsmannstiftung.de/fileadmin/files/BSt/Publikationen /GrauePublikationen/GP_Faktencheck_Gesundheit_Aerztedichte_2.pdf. Accessed 3 June 2019.

27.Rommel A, Bretschneider J, Kroll LE, Prütz F, Thom J. Inanspruchnahme psychiatrischer und psychotherapeutischer Leistungen-Individuelle Determinanten und regionale Unterschiede. Journal of Health Monitoring. 2017; 2(4):3-23.

\section{Tables}

Table 1: Sociodemography, number of treated patients and professional qualification 


\begin{tabular}{|c|c|c|c|c|c|c|}
\hline & Total & $\begin{array}{l}\text { Urban } \\
\text { areas }\end{array}$ & Environs & $\begin{array}{l}\text { Rural } \\
\text { areas }\end{array}$ & $\stackrel{p}{p}$ & $\stackrel{p}{p}$ \\
\hline $\begin{array}{l}\text { Age } \\
\text { (in years) }\end{array}$ & $\begin{array}{c}54.5 \pm \\
8.6 \\
(n=207)\end{array}$ & $\begin{array}{c}53.5 \pm 7.8 \\
(\mathrm{n}=66)\end{array}$ & $\begin{array}{c}54.7 \pm \\
8.6 \\
(n=72)\end{array}$ & $\begin{array}{c}55.4 \pm 9.2 \\
(\mathrm{n}=69)\end{array}$ & 0.190 & 0.630 \\
\hline $\begin{array}{l}\text { Gender } \\
\text { - female } \\
\text { - male }\end{array}$ & $\begin{array}{c}34.6 \% \\
65.4 \% \\
(\mathrm{n}=211)\end{array}$ & $\begin{array}{l}45.5 \% \\
54.6 \% \\
(\mathrm{n}=66)\end{array}$ & $\begin{array}{c}27.0 \% \\
73.0 \% \\
(n=74)\end{array}$ & $\begin{array}{l}32.4 \% \\
67.6 \% \\
(n=71)\end{array}$ & 0.117 & 0.479 \\
\hline Number of patients per month & $\begin{array}{c}344 \pm \\
115 \\
(\mathrm{n}=207)\end{array}$ & $\begin{array}{c}314 \pm 101 \\
(n=65)\end{array}$ & $\begin{array}{l}345 \pm 96 \\
(\mathrm{n}=74)\end{array}$ & $\begin{array}{c}372 \pm 140 \\
(n=68)\end{array}$ & 0.007 & 0.172 \\
\hline $\begin{array}{l}\text { Type of medical practice } \\
\text { - individual practice } \\
\text { - group practice } \\
\text { - joint practice } \\
\text { - medical care centre }\end{array}$ & $\begin{array}{c}51.7 \% \\
6.2 \% \\
40.8 \% \\
1.4 \% \\
(n=211)\end{array}$ & $\begin{array}{c}43.9 \% \\
12.1 \% \\
39.4 \% \\
4.6 \% \\
(n=66)\end{array}$ & $\begin{array}{c}51.4 \% \\
6.8 \% \\
41.9 \% \\
- \\
(n=74)\end{array}$ & $\begin{array}{c}59.2 \% \\
- \\
40.9 \% \\
- \\
(n=71)\end{array}$ & 0.004 & 0.074 \\
\hline $\begin{array}{l}\text { Medical specialist training } \\
\text { - none } \\
\text { - general practice } \\
\text { - internal medicine } \\
\text { - others }\end{array}$ & $\begin{array}{c}6.6 \% \\
77.3 \% \\
23.2 \% \\
3.8 \% \\
(\mathrm{n}=211)\end{array}$ & $\begin{array}{c}9.1 \% \\
77.3 \% \\
25.8 \% \\
1.5 \% \\
(\mathrm{n}=66)\end{array}$ & $\begin{array}{c}8.1 \% \\
70.3 \% \\
31.1 \% \\
8.1 \% \\
(n=74)\end{array}$ & $\begin{array}{c}2.8 \% \\
84.5 \% \\
12.7 \% \\
1.4 \% \\
(\mathrm{n}=71)\end{array}$ & $\begin{array}{l}0.118 \\
0.281 \\
0.051 \\
0.959\end{array}$ & $\begin{array}{l}0.163 \\
0.041 \\
0.008 \\
0.060\end{array}$ \\
\hline $\begin{array}{l}\text { Number of areas of advanced medical } \\
\text { training }\end{array}$ & $\begin{array}{c}1.5 \pm 1.6 \\
(\mathrm{n}=211)\end{array}$ & $\begin{array}{c}1.2 \pm 1.4 \\
(\mathrm{n}=66)\end{array}$ & $\begin{array}{l}1.7 \pm 1.7 \\
(\mathrm{n}=74)\end{array}$ & $\begin{array}{c}1.5 \pm 1.8 \\
(\mathrm{n}=71)\end{array}$ & 0.268 & 0.498 \\
\hline $\begin{array}{l}\text { Advanced medical training } \\
\text { - none } \\
\text { - urgent and emergency care } \\
\text { - palliative medicine } \\
\text { - acupuncture } \\
\text { - manual medicine } \\
\text { - natural medicine } \\
\text { - sports medicine } \\
\text { - nutritional medicine } \\
\text { - addiction basic care } \\
\text { - diabetology } \\
\text { - geriatrics } \\
\text { - psychotherapy } \\
\text { - drivers medical assessment }\end{array}$ & $\begin{array}{l}31.8 \% \\
24.2 \% \\
17.1 \% \\
12.3 \% \\
12.3 \% \\
12.3 \% \\
7.1 \% \\
6.6 \% \\
6.6 \% \\
6.2 \% \\
6.2 \% \\
6.2 \% \\
6.2 \% \\
(\mathrm{n}=211)\end{array}$ & $\begin{array}{l}40.9 \% \\
19.7 \% \\
9.1 \% \\
13.6 \% \\
7.6 \% \\
13.6 \% \\
3.0 \% \\
3.0 \% \\
7.6 \% \\
4.6 \% \\
4.6 \% \\
7.6 \% \\
7.6 \% \\
(\mathrm{n}=66)\end{array}$ & $\begin{array}{c}25.7 \% \\
27.0 \% \\
20.3 \% \\
9.5 \% \\
17.6 \% \\
13.5 \% \\
12.2 \% \\
12.2 \% \\
5.4 \% \\
8.1 \% \\
9.5 \% \\
5.4 \% \\
5.4 \% \\
(\mathrm{n}=74)\end{array}$ & $\begin{array}{l}29.6 \% \\
25.4 \% \\
21.1 \% \\
14.1 \% \\
11.3 \% \\
9.9 \% \\
5.6 \% \\
4.2 \% \\
7.0 \% \\
5.6 \% \\
4.2 \% \\
5.6 \% \\
5.6 \% \\
(\mathrm{n}=71)\end{array}$ & $\begin{array}{l}0.165 \\
0.429 \\
0.051 \\
0.940 \\
0.461 \\
0.492 \\
0.457 \\
0.709 \\
0.905 \\
0.773 \\
0.927 \\
0.647 \\
0.647\end{array}$ & $\begin{array}{l}0.599 \\
0.819 \\
0.899 \\
0.387 \\
0.281 \\
0.494 \\
0.169 \\
0.083 \\
0.683 \\
0.557 \\
0.214 \\
0.952 \\
0.952\end{array}$ \\
\hline
\end{tabular}

C/R: comparison "urban areas" vs. "rural areas"; O/R: comparison "environs" vs. "rural areas"

Table 2: Relative frequency of the most prevalent reasons for consultation from the GP's perspective 
Total Urban areas Environs Rural areas p (C/R)p (O/R)

\begin{tabular}{|c|c|c|c|c|c|c|}
\hline & $(n=201)$ & $(n=65)$ & $(n=71)$ & $(n=65)$ & & \\
\hline $\begin{array}{l}\text { Cardiovascular system, such as: } \\
\text { - high blood pressure } \\
\text { - coronary heart disease } \\
\text { - cardiac arrhythmia } \\
\text { - congestive heart failure }\end{array}$ & $\begin{array}{l}14.6 \% \\
6.7 \% \\
2.6 \% \\
2.0 \% \\
1.9 \%\end{array}$ & $\begin{array}{l}14.8 \% \\
6.8 \% \\
2.6 \% \\
2.1 \% \\
1.7 \%\end{array}$ & $\begin{array}{l}14.8 \% \\
6.8 \% \\
2.8 \% \\
1.9 \% \\
1.8 \%\end{array}$ & $\begin{array}{l}14.3 \% \\
6.4 \% \\
2.5 \% \\
1.9 \% \\
2.1 \%\end{array}$ & $\begin{array}{l}0.737 \\
0.661 \\
0.682 \\
0.653 \\
0.169\end{array}$ & $\begin{array}{l}0.749 \\
0.639 \\
0.355 \\
0.959 \\
0.356\end{array}$ \\
\hline $\begin{array}{l}\text { Musculoskeletal system, such as: } \\
\text { - spinal disorders } \\
\text { - arthrosis of the large joints } \\
\text { - shoulder pain }\end{array}$ & $\begin{array}{l}12.4 \% \\
6.7 \% \\
1.7 \% \\
1.5 \%\end{array}$ & $\begin{array}{c}10.5 \% \\
5.4 \% \\
1.7 \% \\
1.2 \%\end{array}$ & $\begin{array}{l}12.8 \% \\
7.5 \% \\
1.5 \% \\
1.3 \%\end{array}$ & $\begin{array}{c}13.8 \% \\
7.0 \% \\
2.0 \% \\
2.0 \%\end{array}$ & $\begin{array}{r}0.001 \\
0.006 \\
0.289 \\
0.001\end{array}$ & $\begin{array}{r}0.330 \\
0.487 \\
0.041 \\
0.003\end{array}$ \\
\hline $\begin{array}{l}\text { Endocrine/metabolic/nutritional, such as: } \\
\text { - diabetes mellitus (all types) } \\
\text { - lipid metabolism disorder } \\
\text { - weight/dietary problems } \\
\text { - thyroid disorder }\end{array}$ & $\begin{array}{l}12.2 \% \\
3.7 \% \\
2.8 \% \\
2.6 \% \\
1.5 \%\end{array}$ & $\begin{array}{l}12.2 \% \\
3.5 \% \\
2.6 \% \\
2.5 \% \\
1.7 \%\end{array}$ & $\begin{array}{l}12.5 \% \\
3.8 \% \\
3.0 \% \\
2.8 \% \\
1.4 \%\end{array}$ & $\begin{array}{l}11.9 \% \\
3.9 \% \\
2.7 \% \\
2.3 \% \\
1.5 \%\end{array}$ & $\begin{array}{l}0.816 \\
0.304 \\
0.891 \\
0.791 \\
0.237\end{array}$ & $\begin{array}{l}0.662 \\
0.838 \\
0.544 \\
0.306 \\
0.832\end{array}$ \\
\hline $\begin{array}{l}\text { Respiratory system, such as: } \\
\text { - acute infections of the respiratory tract } \\
\text { - chronic obstructive pulmonary disease } \\
\text { - asthma }\end{array}$ & $\begin{array}{l}11.2 \% \\
7.9 \% \\
1.4 \% \\
1.0 \%\end{array}$ & $\begin{array}{l}11.6 \% \\
7.9 \% \\
1.6 \% \\
1.2 \%\end{array}$ & $\begin{array}{c}11.8 \% \\
8.7 \% \\
1.1 \% \\
0.9 \%\end{array}$ & $\begin{array}{c}10.2 \% \\
6.9 \% \\
1.4 \% \\
1.1 \%\end{array}$ & $\begin{array}{l}0.151 \\
0.269 \\
0.449 \\
0.499\end{array}$ & $\begin{array}{r}0.072 \\
0.029 \\
0.107 \\
0.395\end{array}$ \\
\hline $\begin{array}{l}\text { Psychological disorders, such as: } \\
\text { - somatoform disorders } \\
\text { - mild mental disorders } \\
\text { - dementia }\end{array}$ & $\begin{array}{l}10.8 \% \\
3.7 \% \\
2.8 \% \\
1.6 \%\end{array}$ & $\begin{array}{l}11.7 \% \\
4.0 \% \\
2.7 \% \\
1.6 \%\end{array}$ & $\begin{array}{l}10.3 \% \\
3.5 \% \\
2.9 \% \\
1.4 \%\end{array}$ & $\begin{array}{l}10.5 \% \\
3.6 \% \\
2.7 \% \\
1.9 \%\end{array}$ & $\begin{array}{l}0.206 \\
0.471 \\
0.887 \\
0.622\end{array}$ & $\begin{array}{l}0.834 \\
0.858 \\
0.602 \\
0.290\end{array}$ \\
\hline $\begin{array}{l}\text { General/unspecific disorders, such as: } \\
\text { - general fatigue and weakness } \\
\text { - vertigo } \\
\text { - lymph/leg oedema, chronic wounds } \\
\text { - adverse drug reaction }\end{array}$ & $\begin{array}{l}10.2 \% \\
3.8 \% \\
2.0 \% \\
1.4 \% \\
1.2 \%\end{array}$ & $\begin{array}{l}10.7 \% \\
4.3 \% \\
2.2 \% \\
1.2 \% \\
1.3 \%\end{array}$ & $\begin{array}{l}9.8 \% \\
3.5 \% \\
2.0 \% \\
1.5 \% \\
1.1 \%\end{array}$ & $\begin{array}{l}10.2 \% \\
3.5 \% \\
1.9 \% \\
1.7 \% \\
1.1 \%\end{array}$ & $\begin{array}{r}0.578 \\
0.128 \\
0.310 \\
0.009 \\
0.422\end{array}$ & $\begin{array}{l}0.697 \\
0.982 \\
0.974 \\
0.316 \\
0.934\end{array}$ \\
\hline $\begin{array}{l}\text { Digestive system, such as: } \\
\text { - total gastrointestinal tract } \\
\text { - upper gastrointestinal tract } \\
\text { - lower gastrointestinal tract }\end{array}$ & $\begin{array}{l}9.2 \% \\
3.1 \% \\
2.9 \% \\
2.2 \%\end{array}$ & $\begin{array}{l}9.1 \% \\
3.1 \% \\
2.8 \% \\
2.2 \%\end{array}$ & $\begin{array}{l}8.9 \% \\
3.1 \% \\
3.0 \% \\
1.9 \%\end{array}$ & $\begin{array}{l}9.7 \% \\
3.1 \% \\
3.0 \% \\
2.4 \%\end{array}$ & $\begin{array}{l}0.514 \\
0.803 \\
0.571 \\
0.683\end{array}$ & $\begin{array}{l}0.367 \\
0.827 \\
0.879 \\
0.129\end{array}$ \\
\hline $\begin{array}{l}\text { Social problems, such as: } \\
\text { - family, partnership problems } \\
\text { - workplace issues, unemployment }\end{array}$ & $\begin{array}{l}5.0 \% \\
1.3 \% \\
1.2 \%\end{array}$ & $\begin{array}{l}6.4 \% \\
1.5 \% \\
1.5 \%\end{array}$ & $\begin{array}{l}4.6 \% \\
1.2 \% \\
1.1 \%\end{array}$ & $\begin{array}{l}4.1 \% \\
1.1 \% \\
0.9 \%\end{array}$ & $\begin{array}{r}0.001 \\
0.059 \\
0.001\end{array}$ & $\begin{array}{l}0.407 \\
0.555 \\
0.198\end{array}$ \\
\hline $\begin{array}{l}\text { Urological system, such as: } \\
\text { - urinary tract infection } \\
\text { - chronic kidney disease }\end{array}$ & $\begin{array}{l}3.2 \% \\
1.4 \% \\
1.1 \%\end{array}$ & $\begin{array}{l}3.2 \% \\
1.4 \% \\
1.2 \%\end{array}$ & $\begin{array}{l}3.1 \% \\
1.5 \% \\
0.8 \%\end{array}$ & $\begin{array}{l}3.4 \% \\
1.3 \% \\
1.2 \%\end{array}$ & $\begin{array}{l}0.637 \\
0.902 \\
0.869\end{array}$ & $\begin{array}{l}0.420 \\
0.382 \\
0.112\end{array}$ \\
\hline Skin & $2.8 \%$ & $2.4 \%$ & $3.1 \%$ & $3.0 \%$ & 0.074 & 0.759 \\
\hline $\begin{array}{l}\text { Neurological system, such as: } \\
\text { - headache }\end{array}$ & $\begin{array}{l}2.7 \% \\
1.8 \%\end{array}$ & $\begin{array}{l}2.5 \% \\
1.6 \%\end{array}$ & $\begin{array}{l}2.8 \% \\
1.9 \%\end{array}$ & $\begin{array}{l}2.9 \% \\
1.9 \%\end{array}$ & $\begin{array}{l}0.166 \\
0.142\end{array}$ & $\begin{array}{l}0.824 \\
0.777\end{array}$ \\
\hline Ear & $1.7 \%$ & $1.4 \%$ & $1.6 \%$ & $2.0 \%$ & 0.005 & 0.140 \\
\hline Blood, blood-forming org., immune syst. & $1.2 \%$ & $1.3 \%$ & $1.2 \%$ & $1.2 \%$ & 0.544 & 0.994 \\
\hline Eye & $1.1 \%$ & $0.9 \%$ & $1.0 \%$ & $1.2 \%$ & 0.044 & 0.281 \\
\hline
\end{tabular}

C/R: comparison "urban areas" vs. "rural areas"; O/R: comparison "environs" vs. "rural areas".

Table 3: Relative frequency of services from the GP's perspective 
Total Urban areas Environs Rural areas p (C/R)p (O/R)

\begin{tabular}{|c|c|c|c|c|c|c|}
\hline & $(n=211)$ & $(n=66)$ & $(n=74)$ & $(n=71)$ & & \\
\hline Blood tests & $14.9 \%$ & $14.3 \%$ & $13.8 \%$ & $16.6 \%$ & 0.081 & 0.033 \\
\hline Referral to specialist & $14.6 \%$ & $15.3 \%$ & $13.7 \%$ & $14.9 \%$ & 0.810 & 0.360 \\
\hline Continuous care for the chronically ill & $11.9 \%$ & $11.4 \%$ & $13.3 \%$ & $10.9 \%$ & 0.690 & 0.067 \\
\hline Urine analysis & $6.3 \%$ & $6.5 \%$ & $5.5 \%$ & $6.9 \%$ & 0.553 & 0.024 \\
\hline Lifestyle counselling, social counselling & $5.3 \%$ & $6.5 \%$ & $5.5 \%$ & $3.7 \%$ & 0.006 & 0.034 \\
\hline House calls (also: calls at nursing homes) & $4.7 \%$ & $3.7 \%$ & $4.7 \%$ & $5.6 \%$ & 0.020 & 0.303 \\
\hline Psychosomatic basic care & $4.0 \%$ & $5.3 \%$ & $3.6 \%$ & $3.1 \%$ & 0.001 & 0.300 \\
\hline Pain therapy & $3.7 \%$ & $3.1 \%$ & $3.6 \%$ & $4.3 \%$ & 0.148 & 0.403 \\
\hline Electrocardiogram (ECG) & $3.4 \%$ & $3.7 \%$ & $3.2 \%$ & $3.3 \%$ & 0.352 & 0.842 \\
\hline Disease management programme (DMP) & $3.1 \%$ & $2.8 \%$ & $2.9 \%$ & $3.5 \%$ & 0.176 & 0.232 \\
\hline Vaccination & $2.8 \%$ & $3.1 \%$ & $2.6 \%$ & $2.8 \%$ & 0.560 & 0.642 \\
\hline Wound dressing/compression/tamponade & $2.7 \%$ & $1.9 \%$ & $3.0 \%$ & $3.1 \%$ & 0.002 & 0.657 \\
\hline Nutrition counselling & $2.2 \%$ & $2.4 \%$ & $2.1 \%$ & $1.9 \%$ & 0.198 & 0.601 \\
\hline Sonography & $2.2 \%$ & $2.2 \%$ & $2.2 \%$ & $2.3 \%$ & 0.803 & 0.843 \\
\hline Local injection/infiltration & $2.0 \%$ & $1.2 \%$ & $2.6 \%$ & $2.2 \%$ & 0.006 & 0.395 \\
\hline Check-up 35 & $1.9 \%$ & $2.2 \%$ & $2.0 \%$ & $1.6 \%$ & 0.023 & 0.155 \\
\hline Pulmonary function test & $1.5 \%$ & $1.5 \%$ & $1.2 \%$ & $1.7 \%$ & 0.437 & 0.063 \\
\hline Organisation of patient care/support & $1.4 \%$ & $1.6 \%$ & $1.4 \%$ & $1.1 \%$ & 0.079 & 0.205 \\
\hline Scatoscopy & $1.4 \%$ & $1.7 \%$ & $1.3 \%$ & $1.3 \%$ & 0.238 & 0.930 \\
\hline Physical therapy & $1.3 \%$ & $0.9 \%$ & $1.4 \%$ & $1.5 \%$ & 0.177 & 0.792 \\
\hline Skin cancer screening & $1.1 \%$ & $1.2 \%$ & $1.1 \%$ & $0.9 \%$ & 0.163 & 0.434 \\
\hline Social medical assessments & $1.0 \%$ & $0.9 \%$ & $1.1 \%$ & $0.9 \%$ & 0.840 & 0.453 \\
\hline Alternative/natural medicine, acupuncture & $0.9 \%$ & $0.8 \%$ & $1.4 \%$ & $0.6 \%$ & 0.673 & 0.081 \\
\hline Referral to hospital & $0.9 \%$ & $1.0 \%$ & $0.8 \%$ & $0.9 \%$ & 0.442 & 0.407 \\
\hline Early detection of cancer (others) & $0.8 \%$ & $0.7 \%$ & $1.0 \%$ & $0.7 \%$ & 0.889 & 0.175 \\
\hline Ambulatory blood pressure monitoring & $0.7 \%$ & $0.7 \%$ & $0.7 \%$ & $0.6 \%$ & 0.461 & 0.241 \\
\hline Individual health services for direct payer & $0.6 \%$ & $0.6 \%$ & $0.8 \%$ & $0.3 \%$ & 0.073 & 0.063 \\
\hline Cardiac stress test ECG & $0.5 \%$ & $0.6 \%$ & $0.4 \%$ & $0.4 \%$ & 0.521 & 0.969 \\
\hline Palliative therapy & $0.5 \%$ & $0.4 \%$ & $0.4 \%$ & $0.6 \%$ & 0.239 & 0.147 \\
\hline Paediatric services & $0.4 \%$ & $0.3 \%$ & $0.5 \%$ & $0.4 \%$ & 0.528 & 0.752 \\
\hline Incision/drainage/flushing/aspiration & $0.3 \%$ & $0.2 \%$ & $0.4 \%$ & $0.2 \%$ & 0.780 & 0.080 \\
\hline Minor surgery & $0.2 \%$ & $0.1 \%$ & $0.3 \%$ & $0.2 \%$ & 0.162 & 0.200 \\
\hline Ambulatory blood pressure monitoring & $0.2 \%$ & $0.2 \%$ & $0.2 \%$ & $0.3 \%$ & 0.677 & 0.167 \\
\hline Emergency call & $0.2 \%$ & $0.3 \%$ & $0.1 \%$ & $0.1 \%$ & 0.071 & 0.448 \\
\hline Patient education (structured education) & $0.2 \%$ & $0.2 \%$ & $0.3 \%$ & $0.05 \%$ & 0.082 & 0.038 \\
\hline Living will & $0.2 \%$ & $0.2 \%$ & $0.1 \%$ & $0.2 \%$ & 0.639 & 0.114 \\
\hline Closure/fixation/sutures/prosthesis & $0.2 \%$ & $0.08 \%$ & $0.3 \%$ & $0.1 \%$ & 0.032 & 0.150 \\
\hline Instr. manipulation/catheter/intubation & $0.1 \%$ & $0.04 \%$ & $0.2 \%$ & $0.1 \%$ & 0.021 & 0.406 \\
\hline
\end{tabular}

C/R: comparison "urban areas" vs. "rural areas"; O/R: comparison "environs" vs. "rural areas"

Table 4: Association between region and the number of different services by general practitioners: results of a multivariate linear regression adjusted for random effects on the levels of German federal states and administrative districts within the federal states $(n=203)$ 
Model 1

Model 2

Model 3

\begin{tabular}{|c|c|c|c|c|c|c|}
\hline & ß $(95 \% \mathrm{CI})$ & $\mathrm{p}$ & ß $(95 \% \mathrm{CI})$ & $\mathrm{p}$ & B $(95 \% \mathrm{CI})$ & $\mathrm{p}$ \\
\hline $\begin{array}{l}\text { Region } \\
\text { - urban areas vs. rural areas } \\
\text { - environs vs. rural areas }\end{array}$ & $\begin{array}{c}-1.42(-2.75 \text { to } \\
-0.08) \\
-0.90(-2.36 \text { to } \\
0.55)\end{array}$ & $\begin{array}{l}0.038 \\
0.225\end{array}$ & $\begin{array}{c}-0.93(-2.34 \text { to } \\
0.48) \\
-0.55(-1.92 \text { to } \\
0.82)\end{array}$ & $\begin{array}{l}0.196 \\
0.431\end{array}$ & $\begin{array}{l}-0.96(-2.47 \\
\text { to } 0.55) \\
-0.64(-2.01 \\
\text { to } 0.74)\end{array}$ & $\begin{array}{l}0.211 \\
0.365\end{array}$ \\
\hline Age of the physician (in years) & $\begin{array}{c}-0.07(-0.13 \text { to } \\
-0.01)\end{array}$ & 0.016 & $\begin{array}{c}-0.04(-0.11 \text { to } \\
0.02)\end{array}$ & 0.228 & $\begin{array}{l}-0.04(-0.10 \\
\text { to } 0.02)\end{array}$ & 0.238 \\
\hline $\begin{array}{l}\text { Gender of the physician: } \\
\text { male vs. female }\end{array}$ & $\begin{array}{c}1.67(0.58 \text { to } \\
2.77)\end{array}$ & 0.003 & $\begin{array}{c}1.47(0.40 \text { to } \\
2.54)\end{array}$ & 0.007 & $\begin{array}{l}1.47(0.39 \text { to } \\
2.56)\end{array}$ & 0.008 \\
\hline $\begin{array}{l}\text { Postgraduate medical specialist } \\
\text { training } \\
\text { - none (general practitioner) } \\
\text { - general medicine } \\
\text { - internal medicine }\end{array}$ & & & $\begin{array}{c}-3.18(-6.19 \text { to } \\
-0.17) \\
-0.58(-2.65 \text { to } \\
1.50) \\
-1.37(-3.25 \text { to } \\
0.52)\end{array}$ & $\begin{array}{l}0.038 \\
0.584 \\
0.156\end{array}$ & $\begin{array}{c}-2.92(-5.95 \\
\text { to } 0.11) \\
-0.58(-2.66 \\
\text { to } 1.50) \\
-1.43(-3.33 \\
\text { to } 0.45)\end{array}$ & $\begin{array}{l}0.059 \\
0.586 \\
0.135\end{array}$ \\
\hline $\begin{array}{l}\text { Number of areas of advanced } \\
\text { medical training }\end{array}$ & & & $\begin{array}{c}0.29(-0.02 \text { to } \\
0.59)\end{array}$ & 0.066 & $\begin{array}{l}0.31(0.00 \text { to } \\
0.61)\end{array}$ & 0.050 \\
\hline $\begin{array}{l}\text { Type of practice } \\
\text { - group practice vs. individual } \\
\text { practice } \\
\text { - joint practice vs. individual } \\
\text { practice } \\
\text { - medical care centre vs. } \\
\text { individual practice }\end{array}$ & & & & & $\begin{array}{c}0.99(-1.16 \text { to } \\
3.15) \\
0.91(0.18 \text { to } \\
2.01) \\
-0.53(4.69 \text { to } \\
3.62)\end{array}$ & $\begin{array}{l}0.367 \\
0.103 \\
0.802\end{array}$ \\
\hline $\begin{array}{l}\text { Number of treated patients } \\
\text { (per } 100 \text { patients every month) }\end{array}$ & & & & & $\begin{array}{c}0.00(-0.00 \text { to } \\
0.00)\end{array}$ & 0.978 \\
\hline
\end{tabular}

\section{Figures}




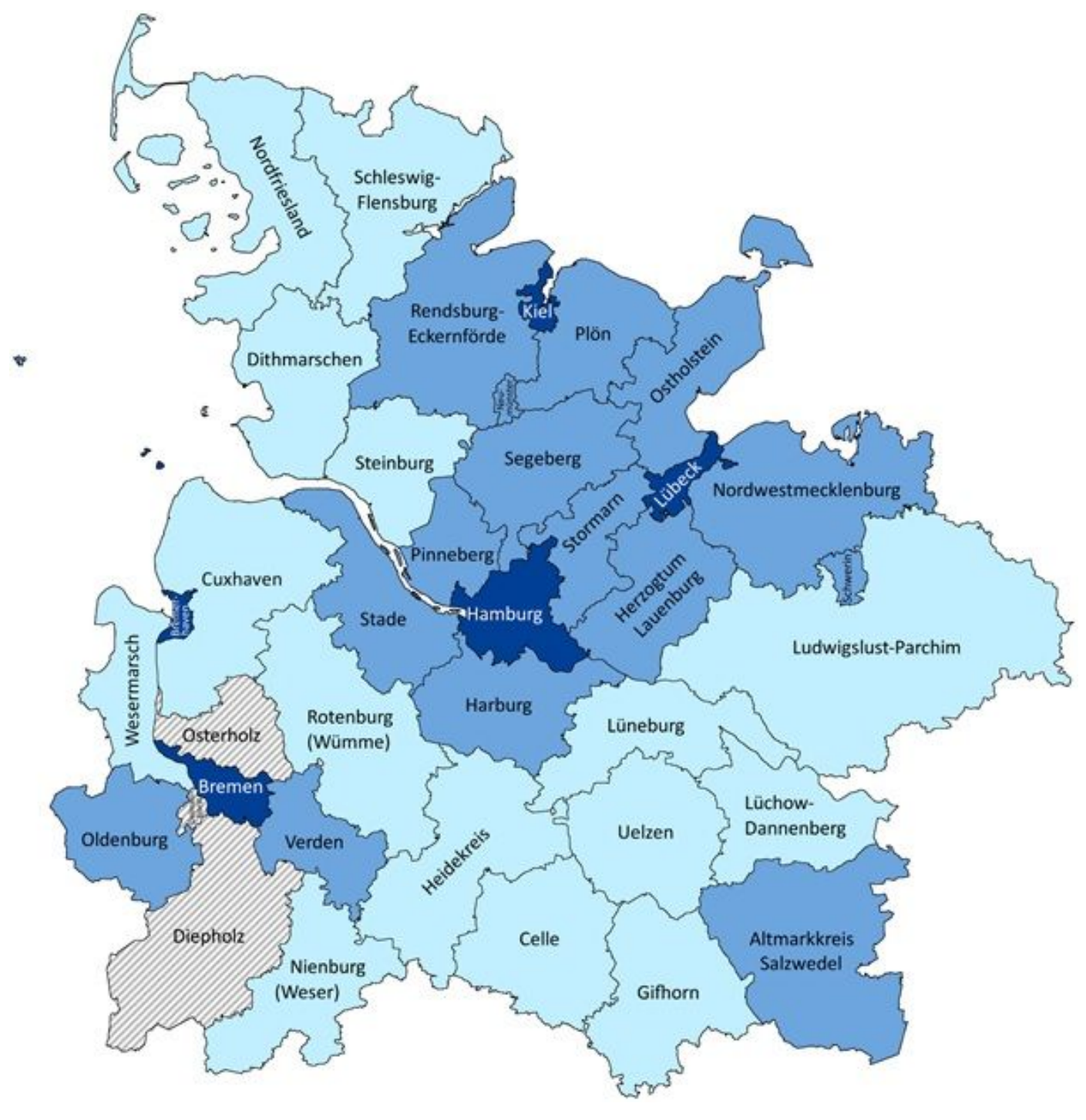

Figure 1

Included administration districts with regional categories @ C GeoBasis-DE / German Federal Agency for Cartography and Geodesy (BKG) 2017 (adjusted). Legend: light blue areas - administration districts of the category "rural areas"; medium blue areas - administration districts of the category "environs"; dark blue areas - administration districts of the category "urban areas"; grey and white shaded areas - not represented administration districts.

\section{Supplementary Files}

This is a list of supplementary files associated with this preprint. Click to download.

- AVFNAdditionalfilesrev.pdf 